\title{
Editorial, January 2021: COVID-19 is here. What comes next?
}

\author{
Editorial, Enero 2021: COVID-19 está aquí. ¿Qué sigue? \\ Ildefonso Rodríguez-Leyva* \\ Department of Neurology, Faculty of Medicine, Hospital Central “Dr. Ignacio Morones Prieto", Universidad Autónoma de San Luis Potosí, SLP, Mexico
}

Medicine, especially neurology, are always challenging. Regardless of the expertise we might assume to possess in the various high specialties that comprise it, new findings and knowledge are generated every day, and it is our job to keep up to speed.

The 2019 coronavirus disease (COVID-19) pandemic emerged in Wuhan, China, as an acute respiratory syndrome. More than a third of the patients develop neurological disorders, which cause direct damage to the nervous tissue, finding edema, and neuronal degeneration, in addition to the presence of the virus itself in the cerebrospinal fluid (CSF). Many viral infections seem to be neurotrophic and this is not the exception, damaging macrophages, microglia, and astrocytes and causing polyneuropathy, encephalitis, and ischemia (among the most common manifestations). It is essential to point out that many patients may not have a respiratory condition but a neurological one. The virus entry is possible through an airway, passing to the olfactory system and arriving at the circulatory system, then to the motor nerve endings, through the rupture of encephalic barriers secondary to hypoxia and edema. The immune response favors the virus with the release of interleukins, cytosines, and tumor-necrosis factor, alterations in the angiotensin-converting enzyme, among other alterations caused by the same virus or the response of the host ${ }^{1}$.

Viruses that infect the central nervous system (CNS) of mammals can have severe consequences and can result in chronic and persistent infections. Murine CNS CoV infection shows that $T$ cells in the acute virus invasion mediate the immune response, and then host regulatory mechanisms appear, many aimed at protecting the CNS integrity. However, sometimes the virus is not eradicated. Both glia and neurons could be a sanctuary for the virus, and the host's defense response could eventually be more harmful to it than to the virus.

The neurological alterations caused by COVID-19 have not been thoroughly studied. Attempts to isolate Severe Acute Respiratory Syndrome CoV-2 (SARSCoV-2) from spinal fluid and autopsies of victims of COVID-19 can play an essential role in understanding precisely what is happening in the affected patient, especially the deeply affected one.

Human CoV can spread from the airways to the CNS by transneuronal and hematogenous routes. On March 4, 2020, in Beijing, China, the virus' presence was demonstrated in the CSF, making the neuroinvasion associated with the virus unquestionable. Considering that encephalitis is associated with high mortality and morbidity, early diagnosis and treatment can improve prognosis. Brain imaging and CSF study are essential if neurological symptoms are present ${ }^{4}$.

A great deal of fear appears in those who have faced the neurological problems associated with the neurotropism and pathogenesis of SARS-CoV-2 related to the infection's acute and long-term consequences. Strategies to

\section{Correspondence:}

*Ildefonso Rodríguez Leyva

E-mail: ilrole@yahoo.com.mx

1665-5044/ (c) 2020 Academia Mexicana de Neurología A.C. Published by Permanyer. This is an open access article under the CC BY-NC-ND license
Date of reception: $11-12-2020$

Date of acceptance: 16-12-2020

DOI: 10.24875/RMN.M20000082
Available online: 11-02-2021

Rev Mex Neuroci. 2021;22(1):1-2

www.revmexneurociencia.com (http://creativecommons.org/licenses/by-nc-nd/4.0/). 
combat these issues must be developed. An acute problem is the loss of the hypothalamus' regulatory capacity, with alteration in glucocorticoid levels associated with neutrophilia and lymphopenia, with a state of hypercoagulation, multiple organ failure, in addition to encephalopathy, encephalitis, cerebral infarction, and Guillain-Barré5.

From the well-known relationship between virus and tumors and neurodegenerative problems, the question has arisen whether this neurotropic virus can undoubtedly be associated with these possibilities. The human T cell leukemia virus type 1, for example, is well known to favor a proliferation that leads to adult T-cell leukemia and to a neurodegenerative process that affects the white substance of both the spinal cord and the brain ${ }^{6}$.

Other viruses, such as the hamster neurotropic strain of measles, cause non-inflammatory encephalopathy in mice, with neuronal loss in the CA1 and CA3 areas of the hippocampus with indirect neurodegenerative effects on the brain due to the activation of the $\mathrm{N}$-methyl-D-aspartate receptors ${ }^{7}$.

Alterations in the cytoskeleton can be induced by herpes simplex virus type 1 (HSV-1) and axonal injury results in significant neuronal damage and neuronal death. Altered microtubule dynamics and tau hyperphosphorylation are possible links between HSV-1 infection and altered neuronal cytoskeleton and may be associated with the neurodegenerative diseases known as tauopathies ${ }^{8}$.

Several viruses are associated with different neurodegenerative diseases, mainly related to neurotropic viruses that can induce neuronal dysfunction and damage, leading to direct death, cell lysis, and induce apoptosis. Regardless of the route of entry, viruses activate both innate and adaptive immune responses. Viral antigens preferentially activate toll-like receptors 3,7 , and 8 , which drive innate and adaptive immune responses by causing neuronal destruction, by direct damage, with the release of free radicals, cell activation, and inflammation; although the immunocompetent host for that virus could eliminate it ${ }^{9}$.
Recently, there is a consideration of the fundamental need to implement programs to monitor people who survive SARS-CoV-2 infections over time, given the possibility that it is a factor that favors the presence of neurodegeneration associated with a viral infection ${ }^{10}$.

DNA viruses such as herpes (HSV, HHV and, EBV, and VZV9 polyomavirus [JCV]), as well as RNA viruses (influenza, measles, rabies, WNV, poliovirus, Echo, Entero, and of course HIV), have been associated with neurodegeneration ${ }^{9}$. Therefore, SARS-CoV-2 may also be associated with a problem that concerns us, given the high prevalence that has been growing as life expectancy has increased.

Even though, life is too short no matter how long it may seem to be, the neurologist's curiosity to continue learning leads us to look for a different future where we can face this new challenge. We must come prepared with new weapons and new prevention, protection, treatment, rehabilitation, and social reintegration measures, given the consequences that this unfortunate pandemic we are facing will surely leave.

\section{References}

1. Wu Y, Xu X, Chen Z, Duan J, Hashimoto K, Yang L, et al. Nervous system involvement after infection with COVID-19 and other coronaviruses. Brain Behav Immun. 2020;87:18-22.

2. Bergmann CC, Lane TE, Stohlman SA. Coronavirus infection of the central nervous system: host-virus stand-off. Nat Rev Microbiol. 2006;4:121-32.

3. Asadi-Pooya AA, Simani L. Central nervous system manifestations of COVID-19: a systematic review. J Neurol Sci. 2020;413:116832.

4. Sun T, Guan J. Novel coronavirus and the central nervous system. Eur J Neurol. 2020;27:e52.

5. ladecola C, Anrather J, Kamel H. Effects of COVID-19 on the nervous system. Cell. 2020;183:16-27.e1.

6. Barmak K, Harhaj E, Grant C, Alefantis T, Wigdahl B. Human T cell leukemia virus Type I-induced disease: pathways to cancer and neurodegeneration. Virology. 2003;308:1-12.

7. Andersson T, Schultzberg M, Schwarcz R, Löve A, Wickman C, Kristensson K. NMDA-receptor antagonist prevents measles virus-induced neurodegeneration. Eur J Neurosci. 1991;3:66-71.

8. Zambrano A, Solis L, Salvadores N, Cortes M, Lerchundi R, Otth C. Neuronal cytoskeletal dynamic modification and neurodegeneration induced by infection with herpes simplex virus Type 1. J Alzheimers Dis. 2008;14:259-69.

9. Zhou L, Miranda-Saksena M, Saksena NK. Viruses and neurodegeneration. Virol J. 2013;10:172.

10. Outeiro TF, Krisko A. SARS-CoV-2 as a trigger of neurodegeneration: thinking ahead. Mov Disord. 2020;5:1106-7. 